\title{
An interdisciplinary framework of limits and barriers to agricultural climate change adaptation
}

\author{
$\underline{\text { M.E. Kragt }}{ }^{\mathrm{a}, \mathrm{b}, \mathrm{c}}$, A. Mugera ${ }^{\mathrm{a}}$, S. Kolikow ${ }^{\mathrm{a}}$ \\ ${ }^{a}$ School of Agricultural and Resource Economics, University of Western Australia, Crawley WA 6009 \\ ${ }^{b}$ Centre for Environmental Economics and Policy, University of Western Australia, Crawley WA 6009; \\ ${ }^{c}$ Sustainable Agriculture Flagship, Ecosystem Sciences, Commonwealth Scientific Industrial Research \\ Organisation, Floreat WA 6014. \\ Email: marit.kragt@uwa.edu.au
}

\begin{abstract}
Agriculture is one of the key economic sectors that are most vulnerable to the impacts of climate change (Pearson et al., 2011). Changes in (variability of) temperature, rainfall and the concentration of $\mathrm{CO}_{2}$ in the atmosphere will directly affect crop and livestock productivity. Although farmers may be particularly knowledgeable in dealing with climate variability, the magnitude of climate change impacts on farming might turn out to go beyond anything that farmers have previously experienced (Stokes and Howden, 2010). This means that adaptive actions are likely to be important to protect farmers' livelihoods from the impacts of unavoidable climate change.
\end{abstract}

There are, however, various limits (absolute obstacles) and barriers (mutable obstacles) to climate change adaptation. The importance of understanding these barriers and limits to support a sustainable and resilient agricultural sector is increasingly acknowledged by academic researchers and government agencies (e.g., Adger et al., 2009; European Commission 2007; Stokes and Howden, 2010; US EPA, 2012). With this increased focus on limits and barriers to adaptation, has come a heightened awareness that the complex, multifaceted nature of climate change requires interdisciplinary research to improve our understanding of obstacles. Unfortunately, the success of inter-disciplinary projects is often hindered by a lack of common definition of limits and barriers to climate change adaptation. In this study, we develop a conceptual model that integrates different understandings of limits and barriers to agricultural climate change adaptation.

Following Pearson et al. (2011), we based our conceptual model on the academic and grey literature as well as expert interviews. The model shows how 'adaptive capacity' and 'willingness to adopt' determine whether a farmer may take adaptive action. Factors that can present limits or barriers to adaptation include biophysical, technological, and socio-economic factors, as well as farmers' personal characteristics and the socio-cultural context in which the farmer operates.

Consultations with experts from various disciplinary backgrounds informed the model development process. Several epistemological challenges were encountered during the study, with disciplinary experts defining limits and barriers to adaptation in different ways. For example, agronomists, economists and biophysical scientists explained that social barriers to adaptive capacity were related to farmers' individual business management skills. Social scientists, on the other hand, used the term social barriers also to indicate that cultural beliefs and values affect a farmers' flexibility or ability to learn new practices. Other epistemological challenges arose when discussing economic limits and barriers. While most experts agreed that adaptation should be aimed at welfare maximisation, different disciplines used variable descriptions of 'welfare'. Many scientists understand economic welfare as a concept that is solely concerned with financial (directly tangible) costs and benefits. Economists in the project, however, incorporated tangible and intangible (non-marketed) values in their definition of economic welfare. It is recommended that future interdisciplinary research between biophysical, economic and social scientists carefully discusses and defines how terms considered in the study are understood across disciplines. The integrated framework developed in the present study provides a guiding tool for such future integrated projects, to help overcome the epistemological challenges that are typically encountered in multidisciplinary research.

Keywords: Adaptation, conceptual modelling, expert opinion, epistemology, interdisciplinary research. 


\section{INTRODUCTION}

The term 'adaptation' refers to conscious adjustments in natural or human systems in response to actual or expected climate changes or its effects, with the aim for a positive outcome. The goal of adaptation is to moderate the harm or exploit the benefits associated with climate change impacts (IPCC, 2001). Successful climate change adaptation hinges on the availability of effective adaptation strategies and the extent to which those strategies are adoptable (Howden et al., 2007). Whether a farmer takes adaptive actions will depend on his willingness to adopt, as well as to the system's adaptive capacity (Howden et al., 2007; Crimp et al., 2010). 'Adaptive capacity' refers to the ability or potential of a system to successfully respond to climate variability and change through behavioural, resource, and technological adjustments (Adger et al., 2007). 'Willingness to adopt' is influenced by individual characteristics and perceptions about climate change impacts (Pannell et al., 2006). Factors that cause deficiencies in either adaptive capacity or willingness to adopt are therefore potential sources of limits and barriers to achieving farm-scale climate change adaptation.

Limits to climate change adaptation are absolute thresholds that render adaptation ineffective as a response to climate change and are largely insurmountable (Adger et al., 2007). Barriers to adaptation are obstacles that can be overcome with, for example, concerted effort, creative management, or changed thinking (Moser and Ekstrom, 2010). Thus far, research on limits and barriers to agricultural adaptation has largely been singledisciplinary in nature, focusing on biophysical, financial, or social factors affecting adaptation (e.g. Bryant et al., 2000; Crimp et al., 2010; Sherwood and Huber, 2010). Such single-disciplinary work cannot account for the wicked character of climate change adaptation problems. Furthermore, the current spread of climate change research across disciplines has resulted in varying definitions, resulting in communication challenges in multi-disciplinary adaptation research (Moser and Ekstrom, 2010). To enable a coordinated response to the challenges that adaptation presents, interdisciplinary research is needed that builds on a common understanding of the issues considered (Kragt et al., 2013). This paper responds to the challenge of aligning varying epistemologies and interpretations by developing a conceptual modelling framework that integrates the multiple dimensions of adaptation. This framework provides a model to improve our understanding of limits and barriers.

Existing frameworks to conceptualise adaptation may be based on asset-based approaches that map, for example, how farmers' productive, social and community assets influence livelihood strategies (e.g. Heltberg et al., 2009). An issue with asset-based frameworks is that they often fail to capture many of the processes and contextual factors that are important for adaptation to occur (Jones et al., 2010). Other conceptual models may use the sustainable livelihood framework, which uses human, economic, social, physical and natural capital as indicators of people's ability to change (Le et al., 2012). Such capitals-based approaches provide a good starting point to map limits and barriers but they may not readily capture intangible factors such as flexibility or innovation (Jones et al., 2010).

The impetus for our work is the lack of a framework that integrates both biophysical and social sciences dimensions in understanding the barriers and limits to adaptation in an agri-environment context. While the framework developed in this study has similarities to other approaches, it aims to provide an interdisciplinary diagnostic tool specifically addressing limits and barriers to adaptation in agriculture, taking intangible assets and processes into account. As with all frameworks, we do not aim to capture the complete complexity of adaptation in agriculture, but rather provide an integrated tool that helps to facilitate coordination among researchers from natural and social science backgrounds, thereby offering a starting point for collaboration in identifying (existing and potential future) limits to adaptation, and work toward overcoming them.

\section{METHOD}

Based on information from the literature, we constructed a preliminary model that included the different conceptual limits and barriers to climate change adaptation in agriculture. This model was subsequently discussed with scientists from various disciplinary backgrounds: agronomists (7), economists (4), sociologists and anthropologists (9), human geographers (2), and climate change modellers (2). Expert consultations were conducted at a three day multi-disciplinary workshop ${ }^{1}$ and in a series of semi-structured interviews between August-September 2011. The Southwest of Western Australia (SWWA) was chosen as a reference point to provide a geographic context to the discussions. Providing experts with a specific context enabled deeper discussions about what might cause limits and barriers to adaptation. The SWWA was chosen because it is one of Australia's major crop producing regions.

\footnotetext{
${ }^{1}$ This workshop was held at Pennsylvania State University (PSU) from 6-8 June 2011, and involved 13 academics from PSU, Monash University, Rhodes University, the University of Cape Town, and the University of Western Australia.
} 


\section{ELEMENTS OF AGRICULTURAL ADAPTATION}

\subsection{Adaptation strategies}

There are many different strategies that farmers can implement to reduce the risk of negative climate change impacts (Table 1). Most of these adaptation strategiessuch as crop insurance, conservation tillage, and income diversification-are simply extensions or intensifications of strategies that farmers already use for dealing with climatic variability.
Table 1. Example farm-level adaptation strategies (Sources: Smit and Skinner, 2002; Howden et al., 2007)

\begin{tabular}{|c|c|}
\hline Adaptation strategy & How can this help? \\
\hline - Conservation tillage & $\begin{array}{l}\text { Reduce the risk of wind erosion, and prevent unnecessary } \\
\text { loss of soil water }\end{array}$ \\
\hline - Crop insurance & $\begin{array}{l}\text { Reduce the risk borne by the farmer in the event of a poor } \\
\text { season }\end{array}$ \\
\hline - Diversify income & $\begin{array}{l}\text { Change income sources to reduce the dependence of } \\
\text { livelihood on climate }\end{array}$ \\
\hline - Drought-tolerant crops & $\begin{array}{l}\text { Change crop types to better reflect the availability of } \\
\text { water }\end{array}$ \\
\hline - Grade banks & $\begin{array}{l}\text { Reduce the risk of soil erosion from high-intensity rainfall } \\
\text { events }\end{array}$ \\
\hline $\begin{array}{l}\text { - Heat-tolerant livestock } \\
\text { varieties }\end{array}$ & $\begin{array}{l}\text { Change livestock varieties to reduce the risk of animal } \\
\text { losses during periods of high temperatures }\end{array}$ \\
\hline - Increase fertilisation & $\begin{array}{l}\text { Prevent the protein content of grain from decreasing as } \\
\text { atmospheric } \mathrm{CO}_{2} \text { increases }\end{array}$ \\
\hline - Irrigation & Prevent crop losses due to insufficient rainfall \\
\hline $\begin{array}{l}\text { - Relocate farming to } \\
\text { less arid regions }\end{array}$ & Change location to an area where it is less risky to farm \\
\hline $\begin{array}{l}\text { - Shift focus towards } \\
\text { cropping }\end{array}$ & $\begin{array}{l}\text { Change enterprise mix to maximise profits without } \\
\text { shifting locations }\end{array}$ \\
\hline $\begin{array}{l}\text { - Shift timing of } \\
\text { livestock reproduction }\end{array}$ & $\begin{array}{l}\text { Reduce the risk of having to buy supplementary feed, by } \\
\text { better matching livestock lifecycle to seasonal availability } \\
\text { of green feed }\end{array}$ \\
\hline $\begin{array}{l}\text { - Supplementary feed } \\
\text { for livestock }\end{array}$ & $\begin{array}{l}\text { Prevent livestock losses by purchasing additional feed } \\
\text { when demand cannot be met by green feed alone }\end{array}$ \\
\hline
\end{tabular}

\subsection{Adaptive capacity and willingness to adapt}

Adaptive capacity in a farming context can be defined as the ability of a farming business to adjust to climate change (including climate variability and extremes) to moderate potential damages, to take advantage of opportunities, or to cope with the consequences (IPCC, 2001) Several studies have addressed adaptive capacity in agriculture (e.g. Sherwood and Huber, 2010), but only a few empirical studies have investigated limits and barriers to adaptation (e.g. O'Brien et al., 2006; Bryan et al., 2009).

In agriculture, a range of factors will affect adaptive capacity, including biophysical constraints, commodity prices, financial markets, available technology, social networks, and institutional support (Antle and Capalbo, 2010). Adaptive capacity will require individuals and institutions to have the capacity to re-organise, sufficient human and social capital to learn, and adequate, readily available information (Stokes and Howden, 2010). Other factors that have been found to influence adaptation at the farm level include wealth, extension services, access to credit, access to fertile land, information on climate change, and government support programs (Bryan et al., 2009). Adaptive capacity at a community level depends on individuals' and organizations' ability to foster learning, willingness to learn from mistakes, engagement in collaborative decision-making arrangements, and encouragement of institutional diversity (Armitage, 2005)

Adaptation is further influenced by a farmer's willingness to adopt new strategies. Unless a farmer perceives a benefit from adoption, he will not adapt. One can draw on the large body of evidence from the rural innovation adoption literature to learn about climate change adaptation (e.g. Feder and Umali, 1993; Pannell et al., 2006; D'Emden et al., 2008). Some of the general factors identified to affect farmers' adoption processes include cognitive variables, values and goals, attitudes and beliefs, and perceptions about the costs, benefits and risks associated with innovations. Distinct challenges associated with climate change that are not fully addressed in the innovation adoption literature include the uncertainty associated with climate change - natural weather variability and the gradual nature of climate change make structural changes difficult to perceive. Therefore, cognitive variables may play a more prominent role in climate change adaptation compared to more general rural innovation adoption (Grothmann and Patt 2005).

\subsection{Limits and barriers}

Research on limits and barriers to climate change adaptation exists in, e.g., biological sciences, agronomy, economics, sociology, psychology, and urban planning (e.g. Grothmann and Patt, 2005; O'Brien et al., 2006; Adger et al., 2009; Crimp et al., 2010; Moser and Ekstrom, 2010; Sherwood and Huber, 2010). The main factors that were found to shape limits and barriers to adaptation are described below. 
Biophysical factors relate to the agro-climatic conditions on the farm and the physiological characteristics of crops and livestock (such as heat tolerance). These can create absolute limits if the farming system cannot adapt beyond certain biophysical or climatic thresholds. For example, crop production will not be possible once a certain temperature or precipitation is reached; extreme weather events that cause flood levels to overtop levees; or increased temperature that lead to insect outbreaks (Pittock and Jones, 2000). Other biophysical factors may present barriers that can be overcome with (e.g.) technological changes and related shifts in resources, land uses and management. For example, increased soil acidity and soil salinity can be addressed by establishing woody perennials and lime application (Pannell et al., 2006), but these adaptations may require costly changes to farm management.

Barriers to adaptation may also arise from social factors, such as the perceptions, values, and norms found 'within society' (Adger et al., 2009). Social barriers to agricultural adaptation broadly arise from: (i) a farmer's personal characteristics, (ii) the socio-institutional context within which the farmer acts, and (iii) the farming system upon which the farmer is acting (Moser and Ekstrom, 2010).

A farmer's personal characteristics include his perceptions of risk; values and goals; and attitudes and beliefs. These can influence his perceptions about the viability of new strategies, and therefore present a barrier to his willingness to adopt. Farmers' knowledge can also act as a barrier by restricting adaptive capacity and, consequently, adaptive behaviour (Howden et al., 2007; Adger et al., 2009).

The institutional context within which a farmer acts can restrict a farm's adaptive capacity directly through rules and regulations, or increase capacity by providing support for adopting certain adaptation strategies (Smit and Skinner, 2002). Institutions, and meso-scale social interactions, are also important sources of farmer knowledge. Social interactions between the farmer and members of his family, as well as interactions with peers, advisors, and others, can influence a farmer's perceptions of the feasibility and/or desirability of different adaptive actions. If different sources convey varying or conflicting information, such interactions may produce barriers to adoption by changing a farmer's (personal) perception of uncertainty and the risks associated with (non-)adoption (Pannell et al., 2006).

Any innovation adoption, be it related to climate change or some other change, will invariably involve certain costs. Economic limits arise when an adaptation technology is not readily available (i.e. expensive to adopt) or if the relative costs to gather information on adaptation are high. Other economic limits are associated with the prices and other benefits produced by the technology, and the risks associated with its use. Weighing all the cost and benefits of investing in adaptation requires (a) information about all the (financial and non-financial) costs and benefits associated with the adaptation strategy; and (b) an understanding about the likely consequences of climate change (the counterfactual). Perceptions about costs and benefits of different adaptation strategies will depend on farmer's personal characteristics. Therefore, farmers' personal characteristics will determine to what extent economic factors impose an actual limit to adaptation.

Finally, technological factors can place a direct limit on adaptation by delineating the range of adaptation strategies available to farmers, since farmers can only adapt to climate change using tools that have already been developed. These technological factors interact with the biophysical, economic and social factors described above. For example, there currently are few technologies that can overcome the biophysical constraint of limited water availability. While more drought-tolerant crops are being developed, the state of current technology will place indirect limits on adaptive activity. As another example, certain technologies may exist but may not be widely accepted from a social perspective, limiting their adoption.

\section{RESULTS AND FINDINGS}

Our work aims to integrate existing, but disparate, knowledge about limits and barriers to agricultural climate change adaptation, into an interdisciplinary system of understanding. Different disciplines were found to have varying understandings of the biophysical, economic, social, and technical factors that may play a role in the adaptation process. Our final conceptual model (Figure 1) presents a compromise that reconciles these different perceptions, and can thus help to overcome the epistemological challenges invariably associated with interdisciplinary research (Kragt et al., 2013).

In our model, available adaptation strategies pass through an adaptive capacity 'filter' to yield a range of strategies that are perceived as viable by the farmer. These are then filtered by the individuals' willingness to adopt, resulting in strategies that a farmer may actually consider. There may be situations where adaptive capacity and willingness to adopt interact: farmers have the capacity to adapt but be unwilling to do so. This interaction is accounted for in the model by including feedback loops between willingness and capacity. 
During the study, it became evident that experts from different backgrounds define limits and barriers to adaptation in different ways. Epistemological challenges were, for example, demonstrated by scientists' various definitions of 'adaptive capacity'. The model shows the multiple sources of limits and barriers to adaptive capacity.

Next to biophysical and technological limits, individual financial and human capital, as well as social factors plays important roles. Human capital (knowledge) influences farmers' capacity to utilise available assets. Social scientists generally explained adaptive capacity by a wide set of personal skills, such as farmers' flexibility or ability to reorganise and learn.

Agronomists, economists and biophysical scientists, on the other hand, tended to stress individuals' "business management skills" as a driver of adaptive capacity. These scientists showed limited familiarity (and sometimes even discomfort) with social factors, such as cultural beliefs and values, that may affect adaptive capacity if they (e.g.) restrict knowledge or technology transfer processes.

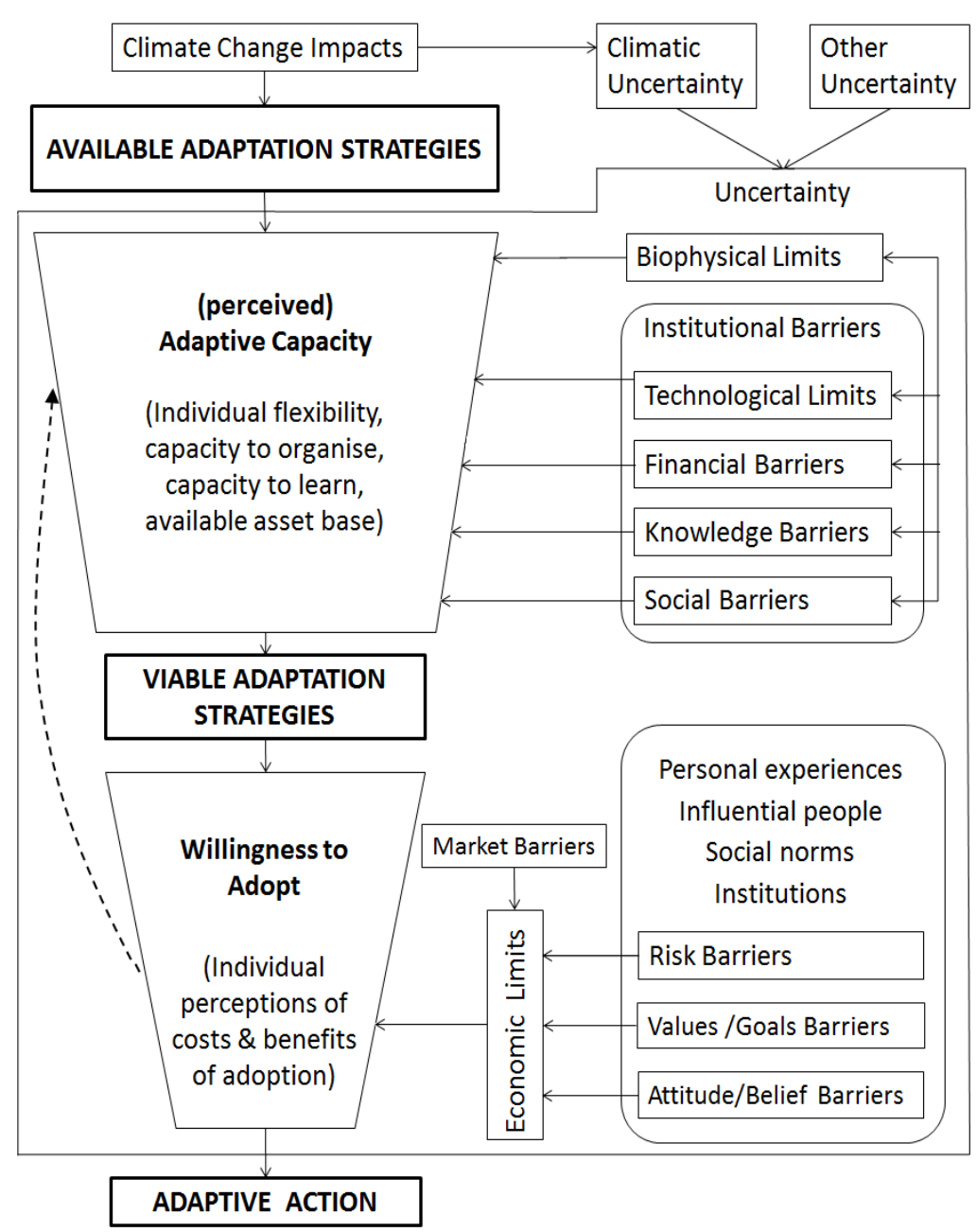

Figure 1. An interdisciplinary framework of limits and barriers to agricultural climate change adaptation.

Other epistemological challenges arose from the use of the term 'economic limits'. While economists tended to incorporate tangible and intangible values in their understanding of economic limits (i.e. market and nonmarket costs and benefits), agronomists typically focussed directly on financial impacts (profitability). Not all consulted experts were comfortable with the term 'economic limits' because of its strong financial connotations. In particular, some social scientist suggested that farmers' decision making will extend beyond 'economic welfare maximisation' (even though economists typically include both financial and non-financial costs and benefits in their definition of welfare). Future interdisciplinary research needs to be aware of the varying understandings of 'economic welfare' and it is suggested that all terminologies are carefully described to ensure that researchers from different disciplinary backgrounds share the same understanding of what is meant.

Experts agreed that external fluctuations in commodity markets (i.e. changes in the costs of inputs or prices of outputs) can create (or remove) market barriers to adaptation. For example, higher wheat prices can increase farm financial capital which can increase a farmer's perceived adaptive capacity. The extent to which price changes restrict willingness to adopt is influenced by individual characteristics such as risk perception, values and goals, and attitudes and beliefs. These characteristics are marked by their dynamic nature, and will vary with farmers' personal traits (such as age, education and experiences). Individual characteristics are also likely to be influenced by other people (including family members, respected peers, and agricultural consultants), social norms, and institutions.

Experts displayed a range of views when asked about the importance of uncertainty as a barrier to adaptation, appearing - to some extent - to stem from varying understandings of 'risk' and 'uncertainty'. Several agronomists argued that farmers won't adopt changes in the face of true uncertainty. They pointed out that 
farmers will only adapt once they have experienced some changes in climate-thus turning climate change into a risk rather than an uncertain factor. Most other experts, however, pointed to uncertainty as one of the biggest barriers to climate change adaptation. Uncertainty was thought to increase the risk that adaptation strategies-implemented now-may prove to be sub-optimal in the future (and possibly costly to rectify).

\section{SUMMARY AND CONCLUSION}

It is increasingly recognised that integrated research is needed to adequately address the limits and barriers to climate change adaptation. Most studies into agricultural adaptation have approached the problem from a single-disciplinary perspective. In this paper, we develop a conceptual model that brings together knowledge from biophysical and social sciences - to serve as an analytical tool for interdisciplinary research on limits and barriers to adaptation in agricultural systems.

The components included in the model reflect the common, integrative understanding of the interviewed experts. However, areas for further research remain. From a theoretical perspective, future research might focus on understanding the interactions between different limits and barriers. To test the applicability of the conceptual model, it is recommended that the model is applied to a practical setting to analyse adaptation options for farmers. From a practical R\&D perspective, researchers can use the model to identify where to direct research efforts, so that limits and barriers to agricultural adaptation can be overcome. Experts particularly highlighted the importance of research and policies to focus on: (1) increasing the range of feasible adaptation strategies; (2) reducing limits to farmers' adaptive capacity; and (3) providing networks and information that can help farmers' overcome barriers to adopting novel technologies.

As a final note, it is worth mentioning that we observed a clear difference between how agronomic and social science experts viewed the interactions between research and farming communities. Agronomy experts had a relatively top-down view, where scientific results would be communicated to farmers through extension officers. They therefore suggested that policies should focus on improving the quality of extension, if we want to improve farmers' knowledge about climate change. Social scientists, on the other hand, advocated a more bottom-up approach of qualitative social research with farmers and communities (Kalaugher et al., 2013). In this bottom-up view, policies should focus on developing a broad civil society where governments, researchers, and local communities interact. The social scientists held the view that the only way that policy makers can hope to change individual's perceptions of climate change, and subsequent adaptive responses, is to assist rural communities in taking ownership of scientific research and development.

\section{ACKNOWLEDGEMENTS}

We gratefully acknowledge the financial support of the Worldwide Universities Network (WUN) in organising the multi-disciplinary workshop on climate change adaptation. We further wish to thank all workshop participants, and the consulted experts for their help in this research. Comments from four anonymous reviewers on an earlier version of the manuscript have been helpful in improving this paper.

\section{REFERENCES}

Adger, W.N., Agrawala, S., Mirza, M.M.Q., Conde, C., O'Brien, K., Pulhin, J., Pulwarty, R., Smit, B. and K. Takahashi (2007). Assessment of adaptation practices, options, constraints, capacity. In: Parry, M.L. (2007). Climate Change: Impacts, Adaptation and Vulnerability. Contribution of Working Group II to the Fourth Assessment Report of the Intergovernmental Panel on Climate Change (IPCC). Cambridge University Press, Cambridge, 717-743.

Adger, W.N., Dessai, S., Goulden, M., Hulme, M., Lorenzoni, I., Nelson, D.R., Naess, L.O., Wolf, J. and A. Wreford (2009). Are there social limits to adaptation to climate change? Climatic Change. 93, 335-354.

Antle, J.M., and S.M. Capalbo (2010). Adaptation of Agriculture and Food Systems to Climate Change: An Economic and Policy Perspective. Applied Economic Perspectives \& Policy. 32(3), 386-416.

Armitage, D. (2005). Adaptive Capacity and Community-Based Natural Resource Management. Environmental Management. 35(6), 703-715.

Bryan, E., Deressa, T.T., Gbetibouo, G.A. and C. Ringler (2009). Adaptation to climate change in Ethiopia and South Africa: options and constraints. Environmental Science \& Policy. 12, 413-426.

Bryant, C.R., Smit, B., Brklacich, M., Johnston, T.R., Smithers, J., Chiotti, Q. and B. Singh (2000). Adaptation in Canadian agriculture to climatic variability and change. Climatic Change. 45, 181-201. 
Kragt et al., An interdisciplinary framework of limits and barriers to agricultural climate change adaptation

Crimp, S.J., Stokes, C.J., Howden, S.M., Moore, A.D., Jacobs, B., Brown, P.R., Ash, A.J., Kokic, P. and P. Leith (2010). Managing Murray-Darling Basin livestock systems in a variable and changing climate: challenges and opportunities. Rangelands Journal, 32, 293-304.

D'Emden, F.H., Llewellyn, R.S. and M.P. Burton (2008). Factors influencing adoption of conservation tillage in Australian cropping regions. Australian Journal of Agricultural \& Resource Economics. 52, 169-182.

European Commission (2007). Adapting to climate change in Europe - options for EU action. Green paper from the Commission to the Council, the European Parliament, the European Economic, Social Committee, the Committee of the regions. Brussels, 26 June 2007.

Feder, G. and D.L. Umali (1993). The Adoption Of Agricultural Innovations - A Review. Technological Forecasting and Social Change. 43, 215-239.

Grothmann, T. and A. Patt (2005). Adaptive capacity and human cognition: The process of individual adaptation to climate change. Global Environmental Change: Human \& Policy Dimensions. 15, $199-213$.

Heltberg, R., P.B. Siegel and S.L. Jorgensen (2009). Addressing human vulnerability to climate change: Toward a 'no-regrets' approach. Global Environmental Change, 19(1), 89-99.

Howden, S.M., Soussana, J.F., Tubiello, F.N., Chhetri, N., Dunlop, M. and H. Meinke (2007). Adapting agriculture to climate change. Proceedings of the National Academy of Sciences. 104, 19691-19696.

IPCC 2001. Climate Change 2001: Synthesis Report, pp.398, Cambridge University Press, Cambridge, UK.

Jones, L., Ludi, E. and S. Levine (2010). Towards a characteristion of adaptive capacity: a framework for analysing adaptive capacity at the local level. Overseas Development Institute, London.

Kalaugher, E., J.F. Bornman, A. Clark and P. Beukes (2013). An integrated biophysical and socio-economic framework for analysis of climate change adaptation strategies: The case of a New Zealand dairy farming system. Environmental Modelling \& Software. 39, 176-187.

Kragt, M.E., Robson, B.J. and C.J.A. Macleod (2013). Modellers' roles in guiding integrative research projects. Environmental Modelling \& Software. 39(1), 322-330.

Le, Q.B., R. Seidl and R.W. Scholz (2012). Feedback loops and types of adaptation in the modelling of landuse decisions in an agent-based simulation. Environmental Modelling \& Software, 27-28, 83-96.

Moser, S.C. and J.A. Ekstrom (2010). A framework to diagnose barriers to climate change adaptation. Proceedings of the National Academy of Sciences. 107, 22026-22031.

O'Brien, K., Eriksen, S., Sygna, L. and L.O. Naess (2006). Questioning complacency: Climate change impacts, vulnerability and adaptation in Norway. Ambio, 35, 50-56.

Pannell, D.J., Marshall, G.R., Barr, N., Curtis, A., Vanclay, F. and R. Wilkinson (2006). Understanding, promoting adoption of conservation practices by rural landholders. Australian Journal of Experimental Agriculture. 46, 1407-1424.

Pearson, L.J., Nelson, R., Crimp, S. and J. Langridge (2011). Interpretive review of conceptual frameworks and research models that inform Australia's agricultural vulnerability to climate change. Environmental Modelling \& Software. 26, 113-123.

Pittock, A.B. and R.N. Jones (2000). Adaptation to what and why? Environmental Monitoring and Assessment. 61(1), 9-35.

Sherwood, S.C. and M. Huber (2010). An adaptability limit to climate change due to heat stress. Proceedings of the National Academy of Sciences. 107, 9552-9555.

Smit, B., and M.W. Skinner (2002). Adaptation options in agriculture to climate change: A typology. Mitigation and Adaptation Strategies for Global Change. 7, 85-114.

Stokes, C.J. and S.M. Howden (2010). Adapting Agriculture to Climate Change - Preparing Australian Agriculture, Forestry, Fisheries for the Future. CSIRO Publishing, Collingwood.

US EPA (2012). Climate Change - Health, and Environmental Effects; Adaptation. US Environmental Protection Agency. http://wwwepagov/climatechange/effects/adaptationhtml. Accessed 12 March (2012). 